\title{
TO COMPARE AND EVALUATE THE EFFECT OF DEXMEDETOMIDINE AS AN ADJUVANT TO LOCAL ANAESTHETIC AGENTS IN SUPRACLAVICULAR BRACHIAL PLEXUS BLOCK FOR ELECTIVE FOREARM SURGERY
}

\author{
Ravi Shankar Sharma ${ }^{1}$, Alok Pratap Singh ${ }^{2}$, Sudhakar Dwivedi ${ }^{3}$
}

13 ${ }^{\text {rd }}$ Year Resident, Department of Anaesthesiology, Shyam Shah Medical College and Associated S. G. M. and G. M. Hospitals, Rewa. ${ }^{2}$ Assosiate Professor, Department of Anaesthesiology, Shyam Shah Medical College and Associated S. G. M. and G. M. Hospitals, Rewa. 3 Professor and HOD, Department of Anaesthesiology, Shyam Shah Medical College and Associated S. G. M. and G. M. Hospitals, Rewa.

\begin{abstract}
A variety of receptor mediated nociception on peripheral sensory axons and the peripheral administration of appropriate drugs (adjuncts) may have analgesic benefit without the disadvantage of systemic adverse effects and it may also allow reduction in the total dose of local anaesthetic used. Recent studies suggest that $\alpha 2$ agonists when combined with local anaesthetics extends the duration of regional anaesthesia. Thus, in the present study, we investigated the effects of adding dexmedetomidine $50 \mu \mathrm{g}$ to a 30 $\mathrm{mL}$ of local anaesthetic solution in supraclavicular brachial plexus block with respect to onset and duration of motor and sensory block and duration of analgesia.
\end{abstract}

\section{METHODS}

Sixty patients scheduled for elective forearm surgery were divided into two equal groups in a randomised double blind fashion. In group $C(n=30), 20 \mathrm{~mL}$ of $0.5 \%$ bupivacaine $+10 \mathrm{~mL}$ of $2 \%$ lignocaine $+0.5 \mathrm{~mL}$ of normal saline and in group $\mathrm{D}(\mathrm{n}=30) 20 \mathrm{~mL}$ of $0.5 \%$ bupivacaine $+10 \mathrm{~mL}$ of $2 \%$ lignocaine $+50 \mu$ dexmedetomidine were given for supraclavicular brachial plexus block using peripheral nerve stimulator. Onset and duration of sensory and motor block were assessed along with total duration of analgesia. Demographic and haemodynamic data were subjected to student's t-test and for statistical analysis of onset time and duration of sensory and motor blocks and total duration of analgesia, unpaired t-test was applied. P-value $<0.05$ was considered as statistically significant and $\mathrm{P}$-value $<0.001$ as highly significant.

\section{RESULTS}

Dexmedetomidine added as an adjuvant to local anaesthetic agents for supraclavicular block shortens onset time and significantly prolongs the duration of sensory and motor blocks and duration of analgesia.

\section{KEYWORDS}

Dexmedetomidine, Bupivacaine, Lignocaine, Supraclavicular Block.

HOW TO CITE THIS ARTICLE: Sharma RS, Singh AP, Dwivedi S. To compare and evaluate the effect of dexmedetomidine as an adjuvant to local anaesthetic agents in supraclavicular brachial plexus block for elective forearm surgery. J. Evolution Med. Dent. Sci. 2016;5(64):4515-4519, DOI: 10.14260/jemds/2016/1031

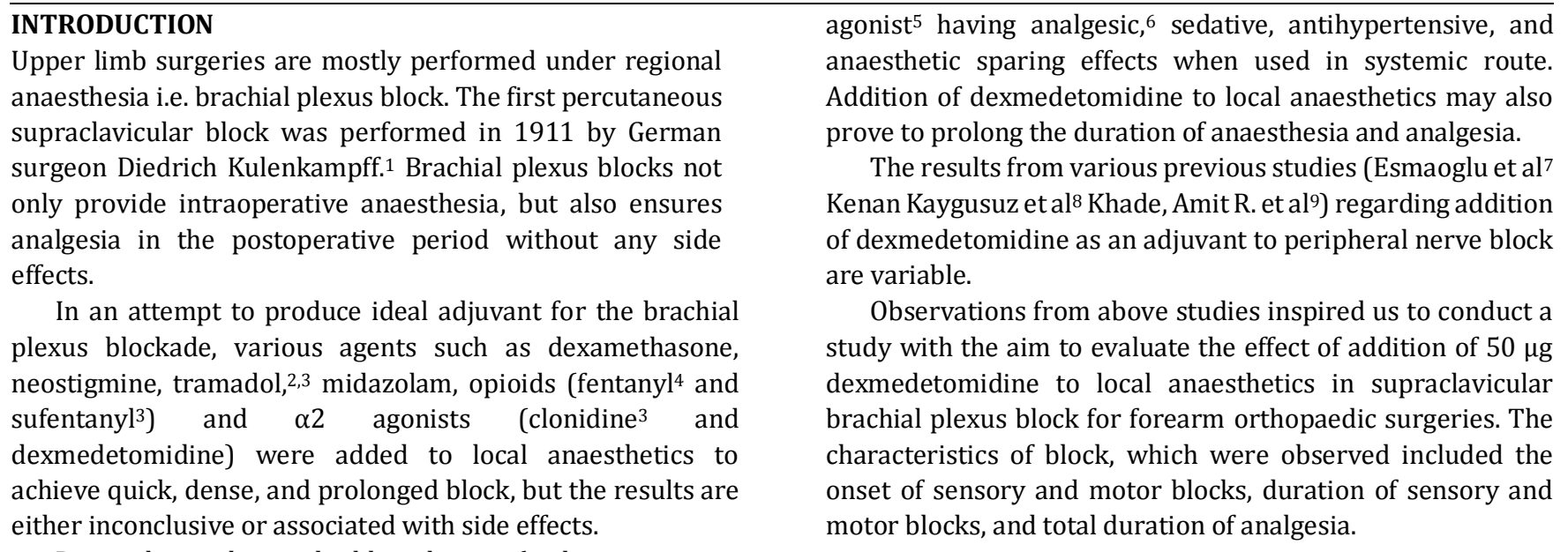

Dexmedetomidine is highly selective (eight times more selective than clonidine), specific and potent $\alpha 2$ adrenergic

Financial or Other, Competing Interest: None.

Submission 02-07-2016, Peer Review 28-07-2016,

Acceptance 02-08-2016, Published 09-08-2016.

Corresponding Author:

Dr. Ravi Shankar Sharma,

\#F-13/4, Arjun Nagar,

New Doctors Colony,

S. S. Medical College,

Rewa-486001, Madhya Pradesh.

E-mail: drravishankarsharma4u@gmail.com

DOI: $10.14260 /$ jemds/2016/1031

\section{MATERIAL AND METHODS}

After obtaining institutional ethics committee approval and written informed consent, 60 adult patients of either sex, aged between 18 to 60 years, weighing between 50 to $70 \mathrm{~kg}$, belonging to ASA class I and II posted for elective forearm surgeries under supraclavicular brachial plexus block were randomly allocated to two equal groups ( $n=30$ in each group) using computer generated random number list. 
Patients in Group C (Control group) received inj. bupivacaine $0.5 \% 20 \mathrm{~mL}+i n j$. lignocaine $2 \% 10 \mathrm{~mL}+i n j$. normal saline $0.5 \mathrm{~mL}$ for the supraclavicular brachial plexus block.

Patients in Group D (Dexmedetomidine group) received inj. bupivacaine $0.5 \% 20 \mathrm{~mL}+$ inj. Lignocaine $2 \% 10 \mathrm{~mL}+\mathrm{inj}$. dexmedetomidine 50 micrograms for the same block.

Patients who refused to take part in the study, presented with any known hypersensitivity to local anaesthetic agents and dexmedetomidine, severe renal, hepatic, or cardiopulmonary abnormality, local skin site infection, neurological, psychiatric, neuromuscular disorder, bleeding disorder, pregnant women, and lactating mother were excluded from study.

Preanaesthetic evaluation was done on the day before surgery and routine examination was carried out assessing general condition of the patient, airway examination of the patient, cardiovascular system, and respiratory system of the patient.

After arrival of patients in operation theatre, intravenous line was secured with an 18 gauge intravenous cannula. The patients were connected to multipara monitor and baseline vitals were recorded. After proper explanation of technique, the patients were placed in the dorsal recumbent position with the head turned away from the site of injection. Under all aseptic precautions, skin infiltration was done with lignocaine $2 \%$ at the site of block prior to block placement. All supraclavicular brachial plexus blocks were performed as described by Winnie. ${ }^{10}$ using 22G, $50 \mathrm{~mm}$ insulated blunt needle [Locoplex (Vygon) needles with extension tubing] and Plexygon nerve stimulator. After an appropriate response was localised with a current $<0.5 \mathrm{~mA}$, the drug (according to the group) was injected in $3 \mathrm{~mL}$ increments after a negative aspiration test with repeat aspirations every $3 \mathrm{~mL}$. Assessments were carried out initially at $5 \mathrm{~min}$ interval thereafter at each minute till the achievement of complete block until 30 minutes. After 30 minutes if the block was considered to be adequate, surgeons were allowed to start the surgery. If the block was considered to be inadequate for surgery, the patients were given general anaesthesia and such patients were not included in the study.

\section{ASSESSMENT}

Assessment of sensory block was done by atraumatic pinprick test using 3-point scale: $0=$ normal sensation, $1=$ loss of sensation of pinprick (analgesia), and 2=loss of sensation of touch (anaesthesia).

It was done at 5 minutes, thereafter at each minute in the dermatomal areas corresponding to median nerve, radial nerve, ulnar nerve, and musculocutaneous nerve till complete sensory block was achieved. Complete sensory block was considered when there was complete loss of sensation in all the dermatomal areas.

Assessment of motor block was carried out at 5 minutes, thereafter at each minute till complete motor blockade. It was determined by thumb abduction (radial nerve), thumb adduction (ulnar nerve), thumb opposition (median nerve), and flexion of elbow (musculocutaneous nerve) according to the modified Bromage scale on a 3-point scale:

Grade 0: Normal motor function with full flexion and extension of elbow, wrist, and fingers.
Grade 1: Decreased motor strength with ability to move the fingers only.

Grade 2: Complete motor block with inability to move the fingers.

Sedation Score was Assessed by Modified Wilson Sedation Scale, 11 which has Scoring from 1 to 4

Score 1: Fully awake and oriented and follows verbal command.

Score 2: Drowsy, eyes closed, but arousable only to commands.

Score 3: Eyes closed, but arousable to mild physical stimulation (Ear lobe tug).

Score 4: Eyes closed and unarousable to mild physical stimulation.

Patient's heart rate, blood pressure, electrocardiogram, respiratory rate, and $\mathrm{SpO} 2$ were monitored and recorded at regular intervals throughout the period of study. Total duration of analgesia was also recorded during the course of study. Patients were monitored for any signs of cardiovascular or central nervous system toxicity (changes in $\mathrm{HR} / \mathrm{BP} / \mathrm{rhythm} /$ signs of CNS stimulation) throughout the study. Any hypersensitivity reaction for the drugs, evidence of pneumothorax, and other adverse events were also monitored. In the postoperative period, the time was noted when the patient first complained of pain at the operative site and hence the total duration of analgesia was calculated.

The results were presented as mean \pm standard deviation (SD) for parametric data and as percentage for nonparametric data. Demographic and haemodynamic data were subjected to Student's t-test and for statistical analysis of onset time and duration of sensory and motor blocks and total duration of analgesia, unpaired t-test was applied, and reconfirmed with the Wilcoxon W and Mann-Whitney U tests. P-value $<0.05$ was considered as statistically significant and P-value $<0.001$ as highly significant. Any adverse effects were analysed using the chi-square/Fischer's exact test. The data were analysed by using Microsoft Excel 2010 for construction of graph and SPSS version 14 software for data analysis.

\section{OBSERVATIONS AND RESULTS}

\section{Demographic Parameter}

Statistically, there was no significant difference in the demographic profile of patients in either group. Both groups were comparable in terms of age, body weight, or male/female $(\mathrm{M} / \mathrm{F})$ ratio.

\begin{tabular}{|c|c|c|c|}
\hline \multicolumn{2}{|c|}{ Parameters } & $\begin{array}{c}\text { Group C } \\
\text { (Control) }\end{array}$ & $\begin{array}{c}\text { Group D } \\
\text { (Dexmedetomidine) }\end{array}$ \\
\hline \multicolumn{2}{|c|}{$\begin{array}{c}\text { Age (yrs.) } \\
\text { (mean } \pm \text { SD) }\end{array}$} & $37.6 \pm 11.87$ & $36.3 \pm 12.58$ \\
\hline \multirow{2}{*}{ Sex } & Male & $22(73.3 \%)$ & $24(80.0 \%)$ \\
\cline { 2 - 4 } & Female & $8(26.7 \%)$ & $6(20.0 \%)$ \\
\hline \multicolumn{2}{|c|}{ Wt. (kg.) } & $65 \pm 10$ & $66 \pm 12$ \\
\hline \multicolumn{3}{|c|}{ Table 1: Showing Demographic Parameters } \\
\hline
\end{tabular}

\section{Onset Time of Sensory and Motor Block}

Onset of sensory block was faster in group D (7.015+/-1.04 min.) as compared to group $C(8.0+/-1.02 \mathrm{~min}$.) and the difference was statistically significant $(\mathrm{p}<0.05)$ while onset of 
motor block was faster in dexmedetomidine group $(14.5 \pm 1.76$ min.) as compared to control group $(17 \pm 1.44 \mathrm{~min}$.) and the difference was highly significant $(\mathrm{p}=<0.001)$.

\begin{tabular}{|c|c|c|c|c|}
\hline Parameter & $\begin{array}{c}\text { Group C } \\
\text { (Control) }\end{array}$ & $\begin{array}{c}\text { Group D (Dex- } \\
\text { medetomidine) }\end{array}$ & $\begin{array}{c}\text { P- } \\
\text { value }\end{array}$ & Remark \\
\hline $\begin{array}{c}\text { Onset Time } \\
\text { for Sensory } \\
\text { Block } \\
\text { (Min.) }\end{array}$ & $8.0 \pm 1.02$ & $7.015 \pm 1.04$ & $<0.05$ & Significant \\
\hline $\begin{array}{c}\text { Onset Time } \\
\text { for Motor } \\
\text { Block (Min.) }\end{array}$ & $17 \pm 1.44$ & $14.5 \pm 1.76$ & $<0.001$ & $\begin{array}{c}\text { Highly } \\
\text { Significant }\end{array}$ \\
\hline \multicolumn{5}{|c|}{ Table 2: Showing Onset Time of } \\
Sensory and Motor Block
\end{tabular}

Duration of Sensory and Motor Block and Duration of Analgesia

Duration of sensory block was longer in dexmedetomidine group (756 $\pm 42.7 \mathrm{~min}$.) as compared to control group (390 $\pm 20.6 \mathrm{~min}$.$) and the difference was highly significant$ $(p<0.001)$ and duration of motor block was also found to be longer in dexmedetomidine group $(639 \pm 35.1 \mathrm{~min}$.) as compared to control group (313 $\pm 9.04 \mathrm{~min}$.) and this difference was also highly significant $(p<0.001)$. The total duration of analgesia was found to be significantly longer in group D (979.67 $\pm 33.53 \mathrm{~min}$.) as compared to group C $(487.66 \pm 15.85$ $\mathrm{min}$.). This difference was clinically and statistically significant $(<0.001)$.

\begin{tabular}{|c|c|c|c|c|}
\hline Parameter & $\begin{array}{c}\text { Group C } \\
\text { (Control) }\end{array}$ & $\begin{array}{c}\text { Group D (Dex- } \\
\text { medetomidine) }\end{array}$ & $\begin{array}{c}\text { P- } \\
\text { value }\end{array}$ & Remark \\
\hline $\begin{array}{c}\text { Sensory } \\
\text { Block (Min.) }\end{array}$ & $390 \pm 20.6$ & $756 \pm 42.7$ & $<0.001$ & $\begin{array}{c}\text { Highly } \\
\text { Significant }\end{array}$ \\
\hline $\begin{array}{c}\text { Motor } \\
\text { Block (Min.) }\end{array}$ & $313 \pm 9.04$ & $639 \pm 35.1$ & $<0.001$ & $\begin{array}{c}\text { Highly } \\
\text { Significant }\end{array}$ \\
\hline $\begin{array}{c}\text { Total Duration } \\
\text { of Analgesia } \\
\text { (Min.) }\end{array}$ & $487.66 \pm 15.85$ & $979.67 \pm 33.53$ & $<0.001$ & $\begin{array}{c}\text { Highly } \\
\text { Significant }\end{array}$ \\
\hline Table 3: Showing Duration of Sensory and Motor Block \\
and Duration of Analgesia \\
\hline
\end{tabular}

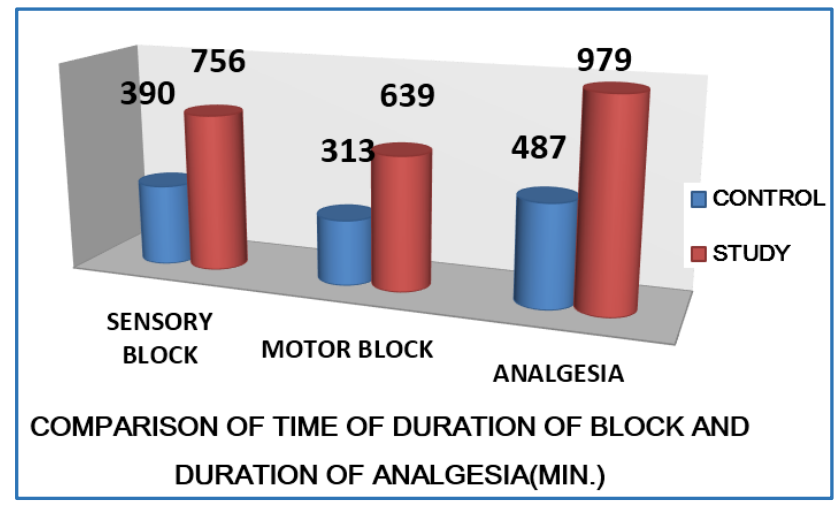

Fig. 1: Showing Comparison of Time of Duration of Block and Duration of Analgesia (Minutes)

\section{Heart Rate}

We clinically noticed lower pulse rate in dexmedetomidine group as compared to control group and this difference was also statistically significant (p-value $<0.05$ ) at 5, 10, 20, 30, 40 min. and at the end of surgery.

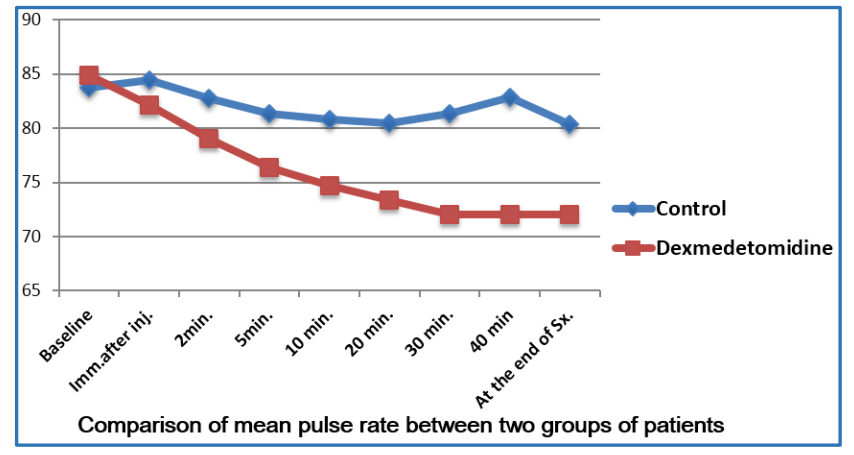

Fig. 2: Showing Comparison of Mean Pulse Rate between Two Groups of Patients

\section{Blood Pressure}

S.B.P., D.B.P., MAP were found to be lower in dexmedetomidine group as compared to control group. Difference in S.B.P. was statistically significant ( $p$-value $<0.05$ ) at 5, 10, 20, 30, $40 \mathrm{~min}$. and at the end of surgery while difference in D.B.P. and M.A.P. was statistically significant at 20,30, $40 \mathrm{~min}$. and at the end of surgery.

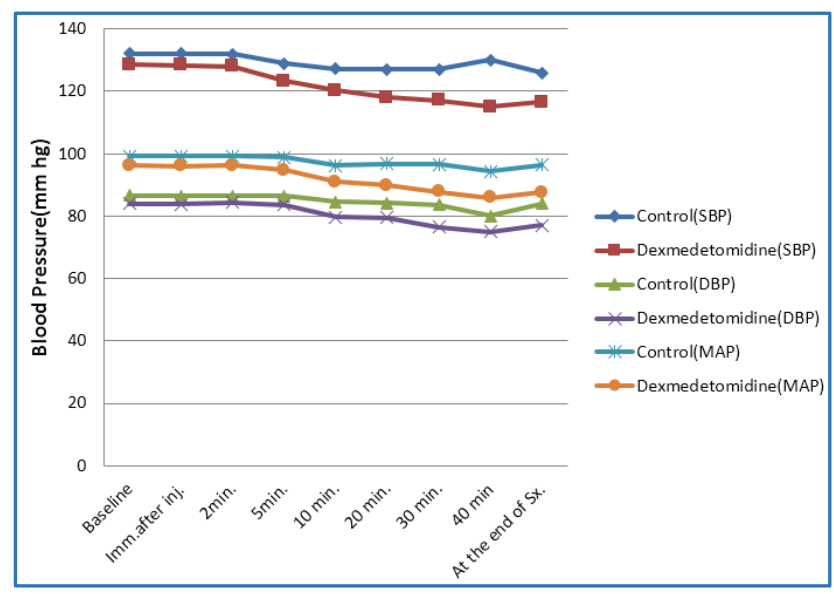

Fig. 3: Showing Comparison of S.B.P., D.B.P., and M.A.P. between Two Groups of Patients

\section{Side Effects}

In our study, while comparing the groups, intraoperative side effects were statistically insignificant. Incidence of hypotension was $\approx 6 \%(2 / 30)$ and that of bradycardia was $\approx 3 \%(1 / 30)$ in dexmedetomidine group, which was statistically not significant. Mean sedation score was 2.3 in dexmedetomidine group as compared to 1 in group C. Other side effects like nausea, vomiting, hypoxaemia, respiratory depression were not observed in either group.

\begin{tabular}{|c|c|c|}
\hline Parameters & Group C & Group D \\
\hline Hypotension & 0 & 2 \\
\hline Bradycardia & 0 & 1 \\
\hline Nausea and Vomiting & 0 & 0 \\
\hline Respiratory Depression & 0 & 0 \\
\hline \multicolumn{2}{|c|}{ Table 4: Showing Side Effects } \\
\hline
\end{tabular}

\section{DISCUSSION}

The aim of proposed study was to evaluate whether additional anaesthetic and analgesic effects could be obtained after 
administration of $\alpha 2$ adrenoceptor agonist, dexmedetomidine, for brachial plexus block.

Dexmedetomidine, the pharmacologically active D-isomer of medetomidine is a highly specific and selective $\alpha 2$ adrenoceptor agonist with $\alpha 2: \alpha 1$ selectivity ratio of $1620: 1$ as compared to $220: 1$ for clonidine, thus decreasing the unwanted side effects of $\alpha 1$ receptors. High selectivity of dexmedetomidine to $\alpha 2-\mathrm{A}$ receptors mediates analgesia, sedation, and anxiolysis. Several mechanisms of action have been suggested to explain the analgesic effect of $\alpha 2$ adrenoceptor agonists in peripheral nerve blocks. Some of these include vasoconstriction around the injection site, direct suppression of impulse propagation through neurons as a result of a complex interaction with axonal ion channels or receptors, local release of enkephalin-like substance, a decrease in localised inflammatory mediators and an increase in anti-inflammatory cytokines through an $\alpha 2$-adrenoceptor mediated mechanism. It also has supraspinal analgesic action via noradrenergic neurons by hyperpolarisation. It inhibits norepinephrine release in descending medullospinal tract.

In present study, we used dexmedetomidine in the dose of 50 microgram. This was based on the observations of the previous studies conducted by Rancourt et $\mathrm{al}^{12}$ and Yoginee Satishrao Patki et al $^{13}$ etc.

The average age of the patients in group $C$ was $37.6 \pm 11.87$ years and that in group D was $36.3 \pm 12.58$ years. Both groups were comparable and there was no statistically significant difference between the two groups in terms of age, gender, and weight. ( $p$ value $>0.05$ ). Both groups predominantly had male patients.

Onset of sensory block was $8.0 \pm 1.02 \mathrm{~min}$. in group $\mathrm{C}$ while it was $7.015 \pm 1.04 \mathrm{~min}$. in group $\mathrm{D}$.This difference was statistically significant ( $p$ value $<0.05$ ).These findings correlate well with the studies of Amit R Khade et al,9 Esmaoglu et al,7 Obayah and Colleagues. ${ }^{14}$ Kenan Kaygusuz et al, ${ }^{8}$ Amay S Ammar and Mahmoud. ${ }^{15}$ Sandhya Agarwal et al. ${ }^{16}$ In Kenan Kaygusuz et al study, onset of sensory blockade was $7.75 \pm 2.22 \mathrm{~min}$. in patients who received levobupivacaine and dexmedetomidine (100 microgram) as compared with patients received levobupivacaine alone $(10.75 \pm 2.55 \mathrm{~min}.) .^{8}$ In Sandhya Agarwal et al ${ }^{16}$ study, onset of sensory blockade was significantly earlier in dexmedetomidine (100 micrograms) group (13.20 $\pm 1.84 \mathrm{~min}$. v/s $19.04 \pm 3.19 \mathrm{~min}$.).

Onset of motor block was $17 \pm 1.44$ min in group $C$ while it was $14.5 \pm 1.76 \mathrm{~min}$ in group D. This difference was statistically significant ( $p$ value $<0.001$ ). Similarly, Marhofer et al ${ }^{17}$ Ammar and Mahmoud ${ }^{15}$ Sandhya Agarwal et al ${ }^{16}$ in their studies found that motor block onset was hastened by the use of dexmedetomidine as an adjuvant in brachial plexus block with local anaesthetics. Sandhya Agarwal et al ${ }^{16}$ noted that the onset of motor block with dexmedetomidine (100 micrograms) was $16.3 \pm 1.7 \mathrm{~min}$. while plain bupivacaine having onset of motor blockade $22.7 \pm 2.8$ minutes. Ammar and Mahmoud $^{15}$ found that onset of motor block was earlier in dexmedetomidine group (15.3 min vs. $22.2 \mathrm{~min}$.).

In present study, mean of total duration of sensory block in group C was $390 \pm 20.6$ minutes and in group D was $756 \pm 42.7$ minutes. This difference was statistically significant ( $\mathrm{p}$ value $<0.001$ ). Mean duration of motor block in group $\mathrm{C}$ was $313 \pm 9.04$ minutes and in group D was $639 \pm 35.1$ minutes. This difference was statistically significant ( $\mathrm{p}$ value $<0.001$ ).These findings support to observations of various earlier studies of
Esmaoglu et al, ${ }^{7}$ Marhofer et al, ${ }^{17}$ Rancourt et al,12 Rachana Gandhi et al,18 Kenan Kaygusuz et al, ${ }^{8}$ Ammar and Mohmoud,15 Sandhya Agarwal et al. ${ }^{16}$

In present study, mean duration of analgesia in group C was $487.66 \pm 15.85$ minutes while it was $979.67 \pm 33.53$ minutes in group D. Significant statistical difference was observed between the two groups with respect to mean duration of analgesia ( $\mathrm{p}$ value $<0.001$ ).

Esmaoglu et $\mathrm{al}^{7}$ observed statistically significant ( $\mathrm{p}$ value $<0.05$ ) longer duration of postoperative analgesia in dexmedetomidine group as compared with plain levobupivacaine. Obayah and colleague ${ }^{14}$ observed that the time for first analgesia was $22 \mathrm{hrs}$. in dexmedetomidine group compared with 14.2 hrs. in plain bupivacaine group. Similar results were observed by Rachana Gandhi et al 18 where the total duration of postoperative analgesia was longer with dexmedetomidine (732.4 $\pm 98.1 \mathrm{~min}$.) as compared with bupivacaine $(194.8 \pm 60.4 \mathrm{~min})$. Kenan Kaygusuz et al observed that the postoperative duration of analgesia was $1279.54 \pm 138.42 \mathrm{~min}$ in dexmedetomidine group as compared with levobupivacaine $(736.80 \pm 45.31 \mathrm{~min}$.). Ammar and Mahmoud $^{15}$ observed that total duration of postoperative analgesia was longer with dexmedetomidine (403 min.) as compared to bupivacaine (233 min.).

In group D, patients had decreased heart rate and reduced mean arterial pressure, which maybe explained with systemic absorption of dexmedetomidine. Presynaptic activation of $\alpha 2$ adrenoreceptor in central nervous system inhibits release of norepinephrine terminating prolongation of pain signals and their postsynaptic activation inhibits sympathetic activity thereby reduces heart rate and blood pressure. Baroreceptor reflex and heart rate response to pressor agent is well preserved with use of dexmedetomidine confirming haemodynamic stability.

No sedation was required in most of the patients in group D. This can be explained on the basis of alpha 2 agonist produce sedation by central action by inhibition of substance $P$ release in the nociceptive pathway at the level of dorsal root neuron and by activation of alpha 2 adrenoreceptors in locus coeruleus.

Respiratory rate and oxygen saturation were comparable in both the groups and there was no statistically significant difference ( $p$-value $>0.05$ ).

In our study, intraoperative side effects were not statistically significant in both the groups. Incidence of hypotension was $\approx 6 \%(2 / 30)$ and that of bradycardia was $\approx 3 \% \quad(1 / 30)$ in dexmedetomidine group, which was statistically not significant. Other side effects like nausea, vomiting, hypoxaemia, and respiratory depression were not observed in either group. Rancourt et al,12 Kenan Kaygusuz et al, ${ }^{8}$ Sarita Swami et al,19 Sandhya Agarwal et al,16 observed similar results in their studies.

\section{CONCLUSION}

Thus, it can be concluded from the present study that $50 \mu \mathrm{g}$ of dexmedetomidine when used in combination with local anaesthetics solution in brachial plexus block gives early onset of sensory and motor block. It significantly prolongs the duration of analgesia to 979 minutes as compared to control group (487 minutes). There was also less requirements of analgesics in first 24-hour postoperatively. The addition dexmedetomidine provides added advantages like conscious 
sedation and haemodynamic stability with minimal side effects.

\section{REFERENCES}

1. Kulenkampff D. Zur anasthesierung des plexus brachialis (On anaesthesia of the brachial plexus). Zentralblatt fur Chirurgie (in German) 1911;38:1337-40.

2. Robaux S, Blunt C, Viel E, et al. Tramadol added to $1.5 \%$ mepivacaine for axillary brachial plexus block improves postoperative analgesia dose-dependently. Anaesth Analg 2004;98(4):1172-7.

3. Antonucci S. Adjuvants in the axillary brachial plexus blockade. Comparison between clonidine, sufentanil and tramadol. Minerva Anaestesiol 2001;67(1-2):23-7.

4. Geze S, Ulusoy H, Ertürk E, et al. Comparison of local anaesthetic mixtures with tramadol or fentanyl for axillary plexus block in orthopaedic upper extremity surgery. Eur J Gen Med 2012;9(2):118-23.

5. Miller R, Kalra P. Miller's anaesthesia, Volumes 1 and 2, 7th edition. Anaesthesiology 2010;112:260-1.

6. Panzer O, Moitra V, Sladen RN. Pharmacology of sedative analgesic agents: dexmedetomidine, remifentanil, ketamine, volatile anaesthetics and the role of peripheral mu antagonists. Crit Care Clin 2009;25(3):451-69, Vii.

7. Esmaoglu A, Yegenoglu F, Akin A, et al. Dexmedetomidine added to levobupivacaine prolongs axillary brachial plexus block. Anaesth Analg 2010;111(6):1548-51.

8. Kayagusuz K, Kol IO, Duger C, et al. Effects of adding dexmedetomidine to levobupivacaine in axillary brachial plexus block. Curr Ther Res Clin Exp 2012;73(3):103-11.

9. Khade AR, Makwana JC, Jethva NK, et al. Evaluation of effect of dexmedetomidine as an adjuvant to bupivacaine in supraclavicular brachial plexus block. National Journal of Integrated Research in Medicine 2013;4(6):122-7.

10. Winnie AP, Franco CD. Supraclavicular approaches to brachial plexus anaesthesia, anaesthesiology. WB Saunders Company 1997;25:353-63.
11. Nemethy M, Paroli L, Williams-Russo PG. Assessing sedation with regional anaesthesia: inter-rater agreement on a modified Wilson sedation scale. Anaesth Analg 2002;94(3):723-8.

12. Rancourt MP, Albert NT, Cote M, et al. Posterior tibial nerve sensory blockade duration prolonged by adding dexmedetomidine to ropivacaine. Anaesth Analg 2012;115(4):958-62.

13. Patki YS, Bengali R, Patil T. Efficacy of dexmedetomidine as an adjuvant to $0.5 \%$ ropivacaine in supraclavicular brachial plexus block for postoperative analgesia. International Journal of Science and Research (IJSR) 2015;4(1):2345-51.

14. Obayah GM, Refaie A, Aboushanab 0, et al. Addition of dexmedetomidine to bupivacaine for greater palatine nerve block prolongs postoperative analgesia after cleft palate repair. Eur J Anaesthesiol 2010;27(3):280-4.

15. Ammar AS, Mahmoud KM. Ultrasound-guided single injection infraclavicular brachial plexus block using bupivacaine alone or combined with dexmedetomidine for pain control in upper limb surgery: a prospective randomised controlled trial. Saudi Journal of Anaesthesia 2012;6(2):109-14.

16. Sandhya A, Aggarwal R, Gupta P. Dexmedetomidine prolongs the effect of bupivacaine in supraclavicular brachial plexus block. Journal of Anaesthesiology, Clinical Pharmacology 2014;30(1):36-40.

17. Marhofer D, Kettner SC, Marhofer P, et al. Dexmedetomidine as an adjuvant to ropivacaine prolongs peripheral nerve block. BJA 2012;110(3):438-42.

18. Gandhi R, Shah A, Patel I. Use of dexmedetomidine along with bupivacaine for brachial plexus block. National Journal of Medical Research 2012;2(1):67-9.

19. Swami SS, Keniya VM, Ladi SD, et al. Comparison of dexmedetomidine and clonidine ( $\alpha 2$ agonist drugs) as an adjuvant to local anaesthesia in supraclavicular brachial plexus block: a randomised double-blind prospective study. Indian Journal of Anaesthesia 2012;56(3):243-9. 